\title{
The posterior communicating artery: morphometric study in 3D angio-computed tomography reconstruction. The proof of the mathematical definition of the hypoplasia
}

\author{
J. Dzierżanowski ${ }^{1}$, A. Szarmach², P. Słoniewski ${ }^{1}$, P. Czapiewski³ ${ }^{3}$ M. Piskunowicz², \\ T. Bandurski ${ }^{4}$, T. Szmuda ${ }^{1}$ \\ ${ }^{1}$ Department of Neurosurgery, Medical University of Gdansk, Poland \\ ${ }^{2}$ Department of Radiology, Medical University of Gdansk, Poland \\ ${ }^{3}$ Department of Pathology, Medical University of Gdansk, Poland \\ ${ }^{4}$ Department of Radiological Informatics and Statistics, Medical University of Gdansk, Poland
}

[Received 17 October 2013; Accepted 19 December 2013]

Background: The aim of this study was to investigate the morphometry of the posterior communicating artery (PCOA), on the basis of angio-computed tomography (CT), and to give proof of the mathematical definition of the term "hypoplasia of the PCOA".

Materials and methods: One hundred 3-dimensional (3D) angio-CT images, performed in adult patients with bilateral reconstruction of the PCOA (200 results) were used to calculate the morphometry of the vessel.

Results: The average length of the vessel on the right side was $14.48 \pm 3.47 \mathrm{~mm}$, and on the left side $14.98 \pm 4.77 \mathrm{~mm}$ (in women $14.75 \mathrm{~mm}$, in men $14.70 \mathrm{~mm}$ ). The mean of the diameter at the "proximal" point (the junction with P1) on the right side was $1.49 \pm 0.51 \mathrm{~mm}$, and on the left $1.46 \pm 0.47 \mathrm{~mm}$ (in women $1.44 \mathrm{~mm}$ and in men $1.51 \mathrm{~mm}$ ). The mean of the diameter in the "distal" part (the connection with ICA) on the right side was $1.4 \pm 0.49 \mathrm{~mm}$, and on the left $1.37 \pm 0.41 \mathrm{~mm}$ (in women $1.38 \mathrm{~mm}$, and in men $1.39 \mathrm{~mm})$. No statistical correlation between the length and the diameter of the PCOA in relation to the sex and side was shown. On the basis of our measurements, we defined the hypoplasia of the artery as the estimated value less than the average diameter minus the standard deviation. The percentage distribution was as follows: the left artery $15.5 \%$, the right artery $24 \%$, women $11.5 \%$, and the men $9 \%$. Similarly to the above parameters, we have not found any statistical differences. The presence of the foetal origin was noted in $25 \%$ of the radiological examinations. The infundibular widening was visualised in $11.5 \%$ of cases of $3 D$ reconstructions. The agenesis of PCOA was found in $9 \%$ (never bilaterally), and in 1 case the unilateral duplication of the artery was observed. No statistical differences between those parameters in relation to sex and the examined side were revealed.

Conclusions: Morphological calculation of the PCOA on the basis of angio-CT from adult patients did not show any statistical differences depending on sex or the investigated side. The presented method of the calculations proved to be useful for the mathematical definition of the term "hypoplasia of the PCOA". (Folia Morphol 2014; 73, 3: 286-291)

Key words: posterior communicating artery, hypoplasia, foetal-type, infundibular widening

Address for correspondence: J. Dzierżanowski, MD, PhD, Department of Neurosurgery, Medical University of Gdansk, ul. Dębinki 7, 80-952 Gdańsk, Poland, tel: +48 5834933 32, fax: +48 5834933 30, e-mail: jaroslawdz@gumed.edu.pl 


\section{INTRODUCTION}

Knowledge of the morphometry of the posterior communicating artery is crucial for neurosurgeons planning the approach to some pathologies in this area, such as aneurysms or tumours in the sella turcica region (pituitary adenoma, craniopharyngioma, meningioma, and glioma of the visual nerve). In the majority of cases, the artery is above the sella turcica, medial to the oculomotor nerve and below the tuber cinereum, and optic chiasm and tract. Some authors suggested that the foetal-type configuration of the posterior communicating artery ( $\mathrm{PCOA})$ can cross above or lateral to the III-rd cranial nerve [8]. The PCoA usually arises from the posteromedial or posterior surface of the wall of $\mathrm{C} 4$ (the communicating segment of the supraclinoid portion of internal carotid artery [ICA]) and joins the precommunicating (P1) segment of the posterior cerebral artery (PCA) in the interpeduncular cistern $[6,12]$. The diameter of the artery is highly variable, from the embryonic kind (foetal-type) with a larger calibre than the P1 (the PCOA is the continuation of the PCA), through to the adult-type with a considerably smaller diameter than P1, to hypoplasia or unilateral agenesis $[7,11,14]$. Many other anatomical variations were described in papers, e.g., funnel-shaped junctional dilatation (infundibular widening), duplicated or fenestrated type of the vessel, and various number and course of the penetrating arteries $[1,3$, $6,11,12]$.

In recent years, a continuous development of radiological techniques of imaging human tissues has been witnessed. That fact makes it possible to use them in a wide range of anatomical studies on morphometry.

The aim of this study is to examine the morphometric of the PCoA in adult patients, using 3-dimensional angio-computed tomography (3D angio-CT) scans to measure the length, calibre, and configuration type of the vessel. On the basis of these measurements, the mathematical definition of the hypoplasia of the PCOA is suggested. The results of this work are discussed based on present literature.

\section{MATERIALS AND METHODS}

In the present study 100 3D angio-CT images, were used to obtain information about the PCoA using General Electric Light Speed 64 VCT. The parameters of the examinations included: the angle of the gantry $0^{\circ}$, the slide thickens $0.6 \mathrm{~mm}$ with the concentration (recons) to $0.2 \mathrm{~mm}$ and $40 \mathrm{~mL}$ of OPTIRAY 350 contrast with the speed flow $4 \mathrm{~mL} / \mathrm{s}$. All the images were sent to the workstation on a standard console and the values of the PCoA (presented below) were calculated using the software programme. These examinations were performed in 100 adult patients ( 56 men and 44 women), and the vessel was measured bilaterally (200 results). All the patients from the examined group were diagnosed at our university department because of the various symptoms (mainly headaches), but no vascular or neurological pathologies were diagnosed. Following parameters of the PCoA were studied: 1) the length; 2 ) the diameter in two places; 3) the foetal type of artery; 4) the infundibular dilatation in the origin of the PCOA from the ICA; and 5) other anomalies, such as the duplication or absence of the artery. All the obtained results were analysed separately (left and right side) with consideration of correlations between the results and sex, but without dividing the patients into different age groups. The calibre of the vessel was measured at 2 points. The first one was at the junction with the ICA, and we named it "distal" or "ICA/PCOA", and the second one at the points of junction with the PCA, which was named in this study "proximal" or "P1/PCoA".

\section{Statistical analysis}

The data obtained were digitised in Excel tables and all statistical analyses were made using the Statistica 8.5 package. The statistical dependencies between the length and the diameter of the artery in relation to sex and side of the body (left, right) were measured using the Student t-test. The differences between the foetal and the infundibular-type of the PCOA in relation to sex and side were assessed using the $\chi^{2}$ test. Probability values of $p<0.05$ were considered significant.

\section{RESULTS}

The average length of the vessel on the right side was $14.48 \pm 3.47 \mathrm{~mm}$, and on the left side $14.98 \pm$ $\pm 4.77 \mathrm{~mm}$. Analysis of the above parameter according to sex showed that in women, the measured length was $14.75 \pm 4.15 \mathrm{~mm}$, and in men $14.70 \pm 4.70 \mathrm{~mm}$.

The mean of the diameter at the "proximal" point (the junction with P1) on the right side was $1.49 \pm$ $\pm 0.51 \mathrm{~mm}$, and on the left $1.46 \pm 0.47 \mathrm{~mm}$. In wo- 
men and men those values were $1.44 \pm 0.48 \mathrm{~mm}$ and $1.51 \pm 48 \mathrm{~mm}$, respectively. The mean of the diameter in the "distal" part (the connection with the ICA) on the right side was $1.4 \pm 0.49 \mathrm{~mm}$, and on the left $1.37 \pm 0.41 \mathrm{~mm}$. In women and men those values were $1.38 \pm 0.47 \mathrm{~mm}$, and $1.39 \pm 42 \mathrm{~mm}$, respectively. No statistical correlation between the length of the PCOA and the diameter of the artery in relations to sex and side was shown.

The hypoplasia of the artery was defined as the estimation less than the average diameter minus the standard deviation. For the proximal part of the PCoA the "borderline size" was $0.93 \mathrm{~mm}$ and for the distal part $0.99 \mathrm{~mm}$. The percentage distribution was as follows: the left artery $15.5 \%$, the right side $24 \%$, women $11.5 \%$, and men $9 \%$. Similarly to the above parameters, no statistical differences were found.

In 18 cases PCoA wasn't found (8 on the right and 10 on the left side). The infundibular widening was found in $11.5 \%$ of cases (in $9.3 \%$ of women, in $14.1 \%$ of men), and in $11 \%$ on the right, and in $12 \%$ on the left side.

The frequency of the foetal origin was noted in $25 \%$ of the radiological examinations. In this group, $28 \%$ were located on the right, and $22 \%$ on the left side, with $27 \%$ of women, and $23 \%$ of men. No statistical differences between those parameters in relation to sex and side of the body were revealed.

\section{DISCUSSION}

The posterior communicating artery is an important element of collateral circulation between anterior and posterior circle of Willis. Additionally, it is the exit point of thalamoperforating arteries and one of them passing anterior to the mammillary bodies is called the premammillary or thalamotuberal artery $[3,6,11,12]$. The number of perforators is variable, between 4 and $14[3,14,15]$. The area supplied by them contains: the premammillary part of III ventricle floor, posterior perforated substance, thalamus, hypothalamus, subthalamus, internal capsule, mammilary bodies, tuber cinereum, optic tract, pituitary stalk, and cerebral peduncle $[2,6$, $12,14]$.

The knowledge of the posterior communicant artery morphometry has clinical implication in at least 2 situations: in neurological examinations related to cerebral ischaemia and hypoplasia of the
PCoA, and in neurosurgical operations, especially the clipping of the aneurysm located in this region. Between 1997 and 2006 we operated on 1,035 patients diagnosed with intracranial aneurysms, 152 of which were aneurysms arising from PCoA (14.7\%). It explains why the artery is still so interesting for clinical doctors.

\section{Length}

In the study, the length of the PCOA on the right side was from 7.8 to $22.6 \mathrm{~mm}$, and on the left side form 5.6 to $25.3 \mathrm{~mm}$. The results were similar to those reported by other authors $(5-25 \mathrm{~mm})$ in anatomical studies on cadavers as well as in radiological measurements $[7,11,14]$.

\section{Infundibular dilatation}

In some papers it is suggested that the funnel-shaped (infundibular dilatation) type of connection of the PCoA with ICA can present a stage in the development of an aneurysm, but others concluded that these dilatations are not preaneurysmal lesions $[5,11]$. In this series, we found infundibular widening in $11.5 \%$ of cases and it is similar to the $6.5-10 \%$ observed by other authors $[1,11]$.

\section{Foetal-type}

The PCoA goes medial to the oculomotor nerve, but in some cases location above or lateral to the III-rd cranial nerve was reported [8]. There is the hypothesis that the foetal-type (embryonal) predisposes to this course. The frequency of the foetal origin is reported to be $22-32 \%[1,11,14]$, and in our study it was approximately $25 \%$. It was found from the calculations in this study that this anatomical variant was more frequent on the right than the left vessel, but without statistical differences.

\section{Diameter}

The vessel diameter is the most frequent parameter analysed by authors for the purpose of comparing anatomical arterial variations. However, it is connected to some problems with interpretation of the results obtained. In studies performed on human brains (anatomical preparations), measurements were performed of the external diameter of the vessels filled with synthetic solution, whereas in radiological examinations, internal calibre of the artery filled with blood and contrast agent were measured. Furthermore, in all quotable papers, the place of measurement 
Table 1. The results of measurements of the morphological parameters of the posterior communicating artery in radiological and anatomical literatures

\begin{tabular}{|c|c|c|c|c|c|c|c|}
\hline Author & $\begin{array}{l}\text { Number of } \\
\text { preparations }\end{array}$ & $\begin{array}{l}\text { Length } \\
{[\mathrm{mm}]}\end{array}$ & $\begin{array}{l}\text { Diameter } \\
{[\mathrm{mm}]}\end{array}$ & $\begin{array}{c}\text { Hypoplasia } \\
{[\%]}\end{array}$ & $\begin{array}{c}\text { Dilation form } \\
{[\%]}\end{array}$ & $\begin{array}{c}\text { Foetal form } \\
{[\%]}\end{array}$ & $\begin{array}{c}\text { Absent } \\
{[\%]}\end{array}$ \\
\hline Bisaria [1] & 126 (a.p.) & 10 & 2.6 & - & 6.3 & 31.7 & 8 \\
\hline Uz and Minc [14] & 30 (a.p.) & 11.94 & 1.42 & - & - & 26.6 & - \\
\hline Pedroza et al. [11] & 50 (а.p.) & - & $\begin{array}{r}\mathrm{ICA}^{*} 1.5 \pm 0.8 \mathrm{R} \\
1.6 \pm 0.6 \mathrm{~L} \\
\mathrm{P}^{*} 1.4 \pm 0.7 \mathrm{R} \\
1.6 \pm 0.6 \mathrm{~L}\end{array}$ & 34 & 10 & 22 & - \\
\hline De Silva et al. [4] & 225 (а.p.) & - & - & 51 & - & - & - \\
\hline Conijn et al. [3] & $\begin{array}{l}92 \text { (MRI exami- } \\
\text { nations) }\end{array}$ & - & $\begin{array}{l}1.23 \text { with perfor. }{ }^{1} \\
1.06 \text { without perfor. }^{2}\end{array}$ & - & - & 19.75 & 11.9 \\
\hline Gabrovsky [7] & 70 (а.p.) & $\begin{array}{l}12.58 \# \\
16.09^{\wedge}\end{array}$ & - & 47.14 & - & - & - \\
\hline Vincentelli et al. [15] & 60 (a.p.) & 16 & 1.8 & - & - & 20 & 14 \\
\hline
\end{tabular}

on the course of the vessel was not found. In addition, a factor like sex seems to be of minor importance than for example age. Even if the study concerns only adults, the difference could arise from the presence of the sclerotic changes. We measured the internal calibre of the artery, after filling with contrast. The thickness of the vessel wall and potential atherosclerotic mass inside the PCoA were not estimated. The diameter of the vessel was within the range from 0.6 to $2.5 \mathrm{~mm}$. In other anatomical estimations performed on the cadavers, the mean external diameter was from 1.0 to $2.9 \mathrm{~mm}[1,11,14,15]$. Conjin et al. [3] in the radiological study (7.0-Tesla magnetic resonance imaging $[\mathrm{MRI}]$ ) showed the difference between the diameters (the measurement of the internal calibre) of PCoAs with and without perforators. The outcome in the first case (the mean) was $1.23 \mathrm{~mm}$ and in the second case 1,06 mm. Gibo et al. [8] measured the diameter of the PCoA which varied from 0.4 to $4.0 \mathrm{~mm}$ (average $1.4 \mathrm{~mm}$ ) and its length ranged from 5.0 to $18 \mathrm{~mm}$ (average $12.0 \mathrm{~mm}$ ). Some authors suggested that the diameter of vessel at dilated junction with ICA (infundibular widening) is bigger by $1 \mathrm{~mm}$ than at the point of connection with the posterior artery [12].

There are no studies showing the potential changes in the diameter in post-mortem arteries of the fixed brains (the shrinking of the wall of the vessel or the widening of the calibre after filling the artery with synthetic material) in comparison to in vivo (functional) situation [4, 10]. In addition, the estimations concern the external measurement of the vessel not the internal calibre. The radiological studies are without mentioned imperfections, but the basic limitation is the sensitivity of these methods. However, many papers reported the results similar to what is shown in Table 1.

\section{Hypoplasia}

A few adjectives describing the dimension of the artery, such as "normal", "small", "hypoplastic" or "absent", can be found in literature on the subject but, unfortunately, with some vagueness of the nomenclature. Many authors use the term "hypoplastic artery" in the description of the operation but it is not a strict definition of this vascular anomaly. There is usually a subjective impression of the surgeons, and it is not based on radiological or anatomical calculations. The introduction of the uniformly quantitative criterions on the estimation could be helpful in resolving this problem. During studies of cerebral ischaemic strokes, some patients were found to have PCoAs with a small diameter (less than $1 \mathrm{~mm}$ ) which could be a risk factor for ischaemic stroke in cases of the ipsilateral ICA occlusion $[2,9,13]$. Probably, this is why the borderline size of $1 \mathrm{~mm}$ is used to describe the PCoA hypoplasia.

In the presented study, a proposed mathematical definition of the PCoA hypoplasia was suggested. 
That parameter was assumed to be the mean of the diameter minus standard deviation. Results of the measurements meant that the value is $0.9 \mathrm{~mm}$. It is analogous to using the borderline size $1 \mathrm{~mm}$ in clinical studies concerning a cerebral ischaemic stroke. It could be the quantitative explanation why the risk of ischaemic complications is increased in cases when the diameter of PCoA is less than $1 \mathrm{~mm}$.

Żmuda and Gielicki [16] are the authors of the interesting idea of calculating the hypoplasia of blood vessel segments on the basis of the morphometry of the renal, iliac and the posterior cerebral artery. They formulated the notion that the vascular asymmetry coefficient as the difference between the mean diameters vascular segments expressed as a percentage of the wider vessel with respect to the major diameter..

Generally, all morphometric studies can be divided into two groups: those performed on the cadavers and those performed on radiological examinations. The disadvantage of the first one is the accessibility to the number of preparations which can be used for another statistical analysis. The second type, unfortunately, also has its limitations connected with the resolution of the obtained picture.

The estimations of this study found 22 hypoplastic arteries on the right and 14 on the opposite side ( $24 \%$ and $15.5 \%)$. None of the subjects had bilateral PCoA hypoplasia. There is a huge disproportion between this result and the outcomes of other studies (31-54\%) presented in the Table $1[4,7,11]$. In the subgroup with PCoA hypoplasia, the variation was higher on the right side but without any significant statistical differences. Chuang et al. [2], who studied 310 subjects with hemispheric and brainstem/cerebellum ischaemic stroke conformed by MRI, noted an opposite result. The incidence of hypoplasia was $19.35 \%$ with the evident predominance of the left side (63.33\%) (Table 1).

\section{Other variation (absence, duplication)}

In these estimations, the agenesis of the posterior communicating artery was found in 9\% (10 cases on the left, and 8 on the right side), and no case was found with both PCoAs absent. In other studies, the absence of PCoA was observed in 8-14\% $[1,3,15]$, based on MRI examinations [3] or on anatomical preparations $[1,15]$.
Bisaria [1] in an own series (126 cranial cavities of adult cadavers) found one PCOA which arose from the ophthalmic artery and 1 case of 3 PCoAs that were located on one side. In this study, interesting anatomical variations were observed. There was 1 case with the unilateral duplication of the PCoA.

\section{CONCLUSIONS}

1. Morphological calculation of the posterior communicating artery on the basis of angio-CT from adult patients did not show any statistical differences depending on the sex or the investigated side.

2. The examinations using radiological techniques are good complements of the morphometry in anatomical preparations.

3. The presented calculations proved to be useful for a mathematical definition of the term "hypoplasia" of the posterior communicating artery. They prove the clinical observations where the diameter of the vessel less than $1 \mathrm{~mm}$ is the cut-off point.

\section{REFERENCES}

1. Bisaria KK (1984) Anomalies of the posterior communicating artery and their potential clinical significance. J Neurosurg, 60: 572-576.

2. Chuang YM, Liu CY, Pan PJ, Lin CP (2008) Posterior communicating artery hypoplasia as a risk factor for acute ischemic stroke in the absence of carotid artery occlusion. J Clin Neurosci, 15: 1376-1381.

3. Conijn M, Hendrikse J, Zwanenburg J, Takahara T, Geerlings M, Mali W, Luijten P (2009) Perforating arteries originating from the posterior communicating artery; a 7.0-Tesla MRI study. Eur Radiol, 19: 2986-2992.

4. De Silva KR, Silva R, Gunasekera WS, Jayesekera RW (2009) Prevalence of typical circle of Willis and the variation in the anterior communicating artery: a study of a Sri Lankan population. Ann Indian Acad Neurol, 12: 157-161.

5. Endo S, Furuichi S, Takab M, Hirashima $Y$, Nishijima M, Takaku A (1995) Clinical study of enlarged infundibular dilatation of the origin of the posterior communicating artery. J Neurosurg, 83: 421-425.

6. Ferriera $M$, de Oliveira $E$, Tedeschi $H$, Wen $H$, Rhoton A (2004) Microsurgical anatomy of the anterior cerebral circulation. In: Le Roux P, Winn R, Newell D eds. Management of the cerebral aneurysm. Saudres, Philadelphia, pp. $27-50$.

7. Gaborovsky N (2002) Microanatomical bases for intraoperative division of the posterior communicating artery. Acta Neurochir, 144: 1205-1211.

8. Gibo H, Lenkey C, Rhoton AL Jr (1981) Microsurgical anatomy of the supraclinoid portion of the internal carotid artery. J Neurosurg, 55: 560-574. 
9. Hoksbergen A, Legemate DA, Csiba L, Csati G, Siro P, Fulesdi B (2003) Absent collateral function of the circle of Willis as risk factor for ischemic stroke. Cerebrovasc Dis, 16: 191-198.

10. Orosz L, Hoksbergen AW, Molnar C, Siró P, Cassot F, Marc-Vergens JP, Fulesdi B (2009) Clinical applicability of a mathematical model in assessing the functional ability of the communicating arteries of the circle of Willis. J Neurol Sci, 287: 94-99.

11. Pedroza A, Dujoyny M, Artero J, Umansy F, Berman SK, Diaz F, Ausman J, Mirchandani H (1987) Microanatomy of the posterior communicating artery. Neurosurgery, 20: 228-235.

12. Rhoton $A$ (2003) Cranial anatomy and surgical approaches. Lippincott Williams \& Wilkins, Illinois, pp. 81-148.
13. Schomer D, Marks M, Steinberg G, Johnstone I, Boothroyd D, Ross M, Pelc N, Enzmann D (1994) The anatomy of the posterior communicating artery as a risk factor for ischemic cerebral infarction. N Engl J Med, 330: 1565-1570.

14. Uz A, Mine E (2004) A morphological study of the posterior communicating artery. Folia Morphol, 63: 397-399.

15. Vincentelli F, Caruso G, Grisoli F, Rabehanta P, Adriamamonjy C, Gouaze A (1990) Microsurgical anatomy of the cisternal course of the perforating branches of the posterior communicating artery. Neurosurgery, 26: 824-831.

16. Żmuda A, Gielicki JS (2007) A novel formula for the classification of blood vessels according to symmetry, asymmetry and hypoplasia. Folia Morphol, 66: 339-345. 